\title{
Magnetic and solar effects on ionospheric absorption at high latitude
}

\author{
Vincenzo Romano, Massimiliano Cerrone, Loredana Perrone and Marco Pietrella \\ Istituto Nazionale di Geofisica e Vulcanologia, Dept. RM2-UF/FAA, Roma, Italy
}

\begin{abstract}
Some periods of intense solar events and of strong magnetic storms have been selected and their effects on the ionospheric $\mathrm{D}$ region have been investigated on the basis of ionospheric absorption data derived from riometer measurements made at the Italian Antarctic Base of Terra Nova Bay (geographic coordinates: 74.69 S, 164.12 E; geomagnetic coordinates: $77.34 \mathrm{~S}, 279.41 \mathrm{E}$ ). It was found that sharp increases in ionospheric absorption are mainly due to solar protons emission with an energy greater than $10 \mathrm{MeV}$. Moreover, the day to night ratios of the ionospheric absorption are greater than 2 in the case of strong events of energetic protons emitted by the Sun, while during magnetic storms, these ratios range between 1 and 2 .
\end{abstract}

Key words ionospheric absorption - solar protons event - magnetic storm - Antarctic region

\section{Introduction}

The electron density below $80 \mathrm{~km}$ in the ionosphere is greatly dependent on the chemistry of this region that is in turn affected by direct solar radiation (Ranta et al., 1984). Under disturbed conditions, one of the principal causes of ionization in the $D$ region is due to the influx of the energetic particles penetrating the atmosphere that increase the electron density and then the ionospheric absorption. Therefore the ionospheric absorption is a suitable parameter to disclose the effects on the lower ionosphere due to the magnetic and solar activity.

During and after magnetospheric storms two types of ionospheric absorption in the $\mathrm{D}$ region

Mailing address: Dr. Vincenzo Romano, Istituto Nazionale di Geofisica e Vulcanologia, Dept. RM2-UF/FAA, Via di Vigna Murata 605, 00143 Roma, Italy; e-mail: Romano@ingv.it can be observed (see, e.g., Ranta et al., 1984, and references therein):

a) An ionospheric absorption increasing at high latitude during the main phase of the magnetospheric storms.

b) An ionospheric absorption increasing during the recovery phase of the magnetospheric storms, clearly separated from the first one, well known as 'Post-Storm Effects' (PSE) (Bremer, 1998) at mid-latitude.

The poleward boundary of PSE has been found to be a function of storm-time, reaching even $\mathrm{L}=4$ (Wagner et al., 1982). As Terra Nova Bay is a polar station located outside the PSE poleward boundary, the first component (a) is expected to be the main effect of magnetic perturbations on the absorption data.

Another important type of absorption that can occur at high latitudes, is the so-called Polar Cap Absorption (PCA). This event is caused by energetic protons emitted by the Sun in connection with major solar flares. The main effects of PCA absorption are seen at lower altitude $(60,70 \mathrm{~m})$ more than other types of absorption due for example to magnetospheric storms. The chemistry of the ionized constituents is markedly different and this 

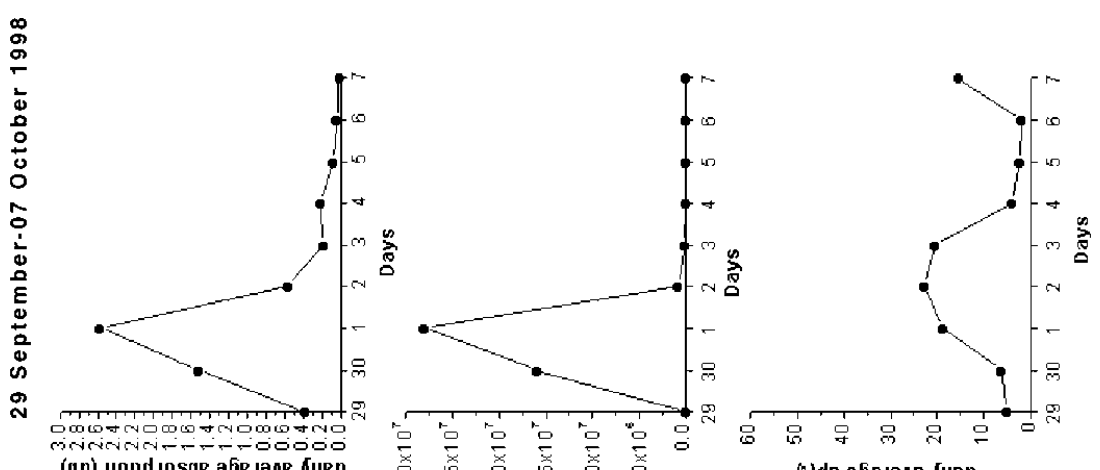

$\stackrel{人}{\sim} \ddot{0}$ (qр) uo!nd Josqe aGe Ja
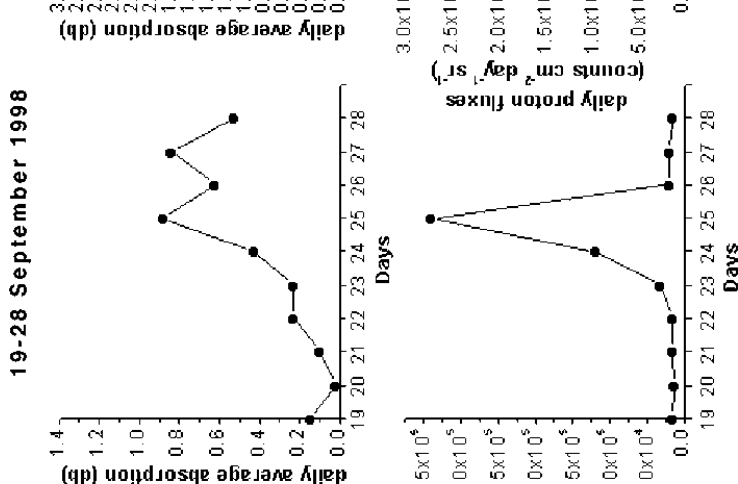

(1) de a jejane M!ep

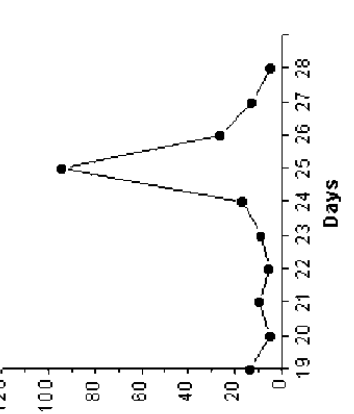

()
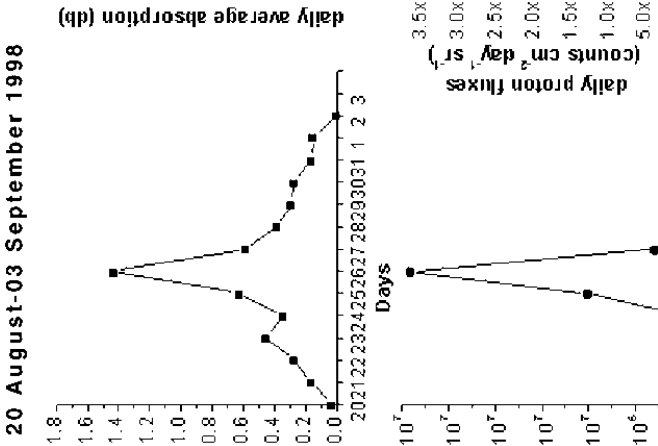

(1)de абенале אи!ер

(2)

(?)
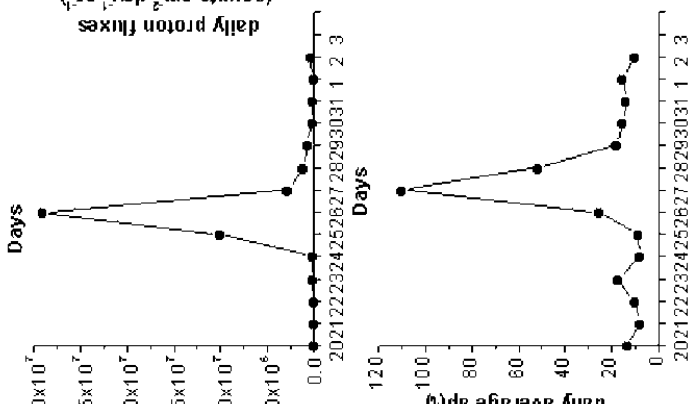

蒡 ()

(qp) nonduosqe afie sane AlIE

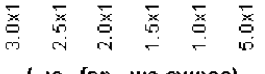

(1)de afiesane 실

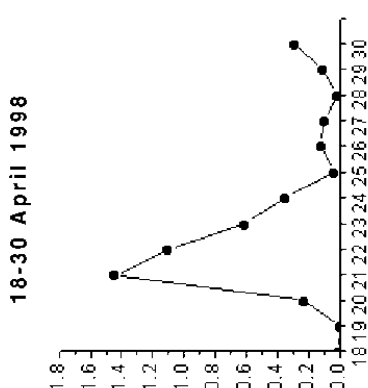

(qp) uopd uosqe a бе sane. Al!ep
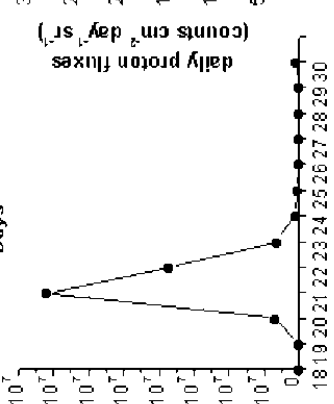

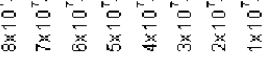

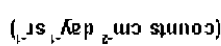
saxily woloud K!!ep

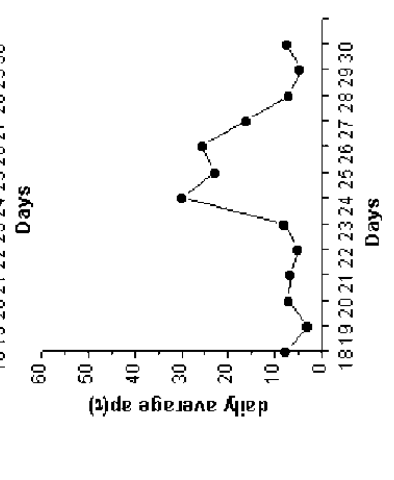

(0) 
probably gives rise to the diurnal variation of PCA. During a PCA the radio absorption measured by riometers by day is typically 2 or more times larger than by night (Ranta et al., 1984). Therefore the day to night absorption ratio can be used to verify that a PCA phenomenon is occurring. The day to night ratios are calculated on the basis of the day-time and night-time ionospheric absorption values. The boundary between day (sunrise) and night (sunset) is generally determined by the solar zenith angle $\chi=90^{\circ}$. Hargreaves (1993) found that at sunset and during a PCA, a significant decay of electron density can be observed for $\chi=96^{\circ}$, corresponding to a height of about $60 \mathrm{~km}$, i.e. the lower ionospheric region here investigated. So, in this study, the day to night ratios at solar zenith angle $\geq 90^{\circ}$ were carried out for some periods of strong solar and magnetic events in 1998 (Section 2). The results are presented and discussed in Sections 3 and 4.

\section{Data analysis}

Ionospheric absorption data (UT), the time weighted magnetic index ap $(\tau)$ (UT), and the solar protons flux (UT) (monitored by the NOAA GOES-8 satellite in geo-synchronous orbit) were considered for the period 1st January 31st December 1998.

Ionospheric absorption data (A2 method) are derived from 1 min cosmic noise measurements recorded at Terra Nova Bay Riometer station (30 MHz) (Cerrone et al., 1996; De Franceschi et al., 1997). The time-weighted accumulation index ap $(\tau)$ (Wrenn, 1987), based on the history of the geomagnetic index $a p$, is considered to represent the magnetic activity effects on the ionosphere. In fact, it has been shown that $a p(t \cong 0.8)$, that corresponds to a $15 \mathrm{~h}$ time delay, is better correlated with the ionospheric parameters, at least in the $F$ region (for details see $\mathrm{Wu}$ and Wilkinson, 1995; Perrone and De Franceschi, 1999; Perrone et al., 2001).

Firstly, strong magnetic storms were selected on the basis of the daily mean of ap $(\tau) \geq 30$ (De Franceschi et al., 1999). Some days before and after the onset of the storm were also taken into account to study the behaviour of the ionospheric absorption before and after the storm. This procedure disclosed the following 3 periods: April 18-30 1998, August 20 September 031998 and September 19-28 1998. Another time-interval was considered from September 29 to October 7 1998, characterized by a strong protons emission event without any important magnetic activity. Figure 1a-d plots the daily mean of the ionospheric absorption (calculated from the absorption values at the first minute of each hour of the day), the daily solar protons flux with energies $>10 \mathrm{MeV}$, and the daily mean of $a p(\tau)$ for each selected period: high correlation between the absorption and solar protons flux maxima can be recognized.

The hourly mean of absorption values (calculated on the basis of $1 \mathrm{~min}$ cosmic noise sampling) during sunset transition between $\chi=87^{\circ}$ and $\chi=102^{\circ}$ both for the days of solar protons flux and ap $(\tau)$ maxima are reported in tables I and II. Moreover, the day to night ratios of the ionospheric absorption obtained by considering $\chi=90^{\circ}$ as sunrise and $\chi=96^{\circ}$ as sunset have been calculated (table III).

\section{Results and discussion}

A careful inspection of fig. 1a-d leads to the following main considerations:

- The period April 18-30 shows a ionospheric absorption peak which occurred on 21 st due to the solar proton event (associated with a solar flare at 20 classified as M1), that started on 20th, reached its maximum on 21 st and stopped on 24th. During this period the ionospheric absorption remained relatively high. A moderate magnetic storm (April 24, ap $(\tau)=30$ ) can be observed probably due to a coronal mass ejection which started on 21 st. As on 24th, the proton flux remained relatively high $\left(1.1 \cdot 10^{6}\right.$ counts . $\mathrm{cm}^{-2} \cdot$ day $\left.^{-1} \cdot \mathrm{sr}^{-1}\right)$, most likely both the solar proton event and the magnetic storm affected the ionospheric absorption value on 24th, but it is not clear which phenomenon gave the major contribution.

- From August 20th to September 3rd the ionospheric absorption that maximized on August 26th was due to the solar proton event that started on 24th (in conjunction to a solar 
Table I. Hourly ionospheric absorption data as function of the solar zenith angles between $87^{\circ}$ and $102^{\circ}$; the days where the solar proton flux affects the ionospheric absorption more than the magnetic storm were considered.

\begin{tabular}{ccc}
\hline \hline Date & Solar zenith angle & Ionospheric absorption $(\mathrm{dB})$ \\
\hline 21 April 1998 & $87^{\circ}$ & 3.67 \\
$90^{\circ}$ & 2.46 \\
$93^{\circ}$ & 1.59 \\
$96^{\circ}$ & 0.89 \\
$99^{\circ}$ & 0.68 \\
26 August 1998 & $102^{\circ}$ & 0.58 \\
& $87^{\circ}$ & 3.21 \\
& $90^{\circ}$ & 2.46 \\
& $93^{\circ}$ & 1.60 \\
$96^{\circ}$ & 1.73 \\
& $99^{\circ}$ & 1.73 \\
$102^{\circ}$ & 1.40 \\
& $87^{\circ}$ & 1.08 \\
& $90^{\circ}$ & 0.79 \\
& $93^{\circ}$ & 0.61 \\
& $96^{\circ}$ & 0.60 \\
& $99^{\circ}$ & 0.60 \\
& $102^{\circ}$ & 0.41 \\
& $87^{\circ}$ & 1.94 \\
& $90^{\circ}$ & 0.95 \\
& $93^{\circ}$ & 0.95 \\
$96^{\circ}$ & 0.62 \\
& $99^{\circ}$ & 0.45 \\
& $102^{\circ}$ & 0.45 \\
& &
\end{tabular}

flare classified as X1/3B), reached its maximum on 26th, and stopped on 29th. The strong magnetic perturbation on August 27th should also be due to the same solar flare. The ionospheric absorption value on 27 th depends on both the solar proton event and the magnetic storm, the proton flux being relatively high on 27 th $\left(2.8 \cdot 10^{6}\right.$ counts $\left.\cdot \mathrm{cm}^{-2} \cdot \mathrm{day}^{-1} \cdot \mathrm{sr}^{-1}\right)$ and the magnetic activity very strong $(\operatorname{ap}(\tau)=110)$ but, as in the previous case, it is difficult to assess a priori where the main contribution came from.

- The period September 19-28 showed an increase in ionospheric absorption starting from 24 th up to 28 th with two peaks on 25th and 27th. As a magnetic storm evolved between 24th and 26 th with a strong maximum on 25 th, just when a solar protons emission occurred (these two events were probably due to the solar flare classified as M7/3B started on 23), both the phenomena concurred to the absorption growth. Given the rather low level of proton flux $\left(2.2 \cdot 10^{4}\right.$ counts $\cdot \mathrm{cm}^{-2} \cdot$ day $^{-1}$. $\left.\mathrm{sr}^{-1}\right)$ and magnetic activity $(\operatorname{ap}(\tau)=13)$, the absorption peak observed on 27th could be better investigated by using a local geomagnetic index.

- A sudden increase in the ionospheric absorption from September 30th with a peak observed on October 1st was due to the solar proton event (associated to a solar flare occurring on 30th September of importance M2/2N.) that reached its maximum the same day.

The hourly mean values (tables I and II) and the day to night ratios (table III) of the absorption 
Table II. Hourly ionospheric absorption data as function of the solar zenith angles between $87^{\circ}$ and $102^{\circ}$; the days where the magnetic storm affects the ionospheric absorption more than the solar proton flux were considered.

\begin{tabular}{ccc}
\hline \hline Date & Solar zenith angle & Ionospheric absorption $(\mathrm{dB})$ \\
\hline 24 April 1998 & $87^{\circ}$ & 0.67 \\
$90^{\circ}$ & 0.59 \\
$93^{\circ}$ & 0.49 \\
$96^{\circ}$ & 0.45 \\
$99^{\circ}$ & 0.51 \\
$102^{\circ}$ & 0.51 \\
25 September 1998 & $87^{\circ}$ & 0.37 \\
& $90^{\circ}$ & 0.35 \\
& $93^{\circ}$ & 0.35 \\
$96^{\circ}$ & 0.53 \\
$99^{\circ}$ & 0.53 \\
\hline
\end{tabular}

Table III. Day to night ratios for proton fluxes and magnetic storm events calculated choosing $\chi=90^{\circ}$ (sunrise) and $\chi=96^{\circ}$ (sunset).

\begin{tabular}{cccc}
\hline \hline Proton fluxes events & Day to night ratios & Magnetic storm events & Day to night ratios \\
\hline 21 April 1998 & 6.52 & 24 April 1998 & 1.64 \\
26 August 1998 & 2.82 & 25 September 1998 & 1.40 \\
27 August 1998 & 2.00 & & \\
01 October 1998 & 15.79 & & \\
\hline
\end{tabular}

were considered as related to the occurring days of proton flux and of magnetic storm maxima in order to identify, as far as possible, which phenomenon causes the ionospheric absorption.

Table I shows a significant decrease of the ionospheric absorption as a function of the solar zenith angle from $\chi=87^{\circ}$ to $\chi=102^{\circ}$. In particular, at $\chi=96^{\circ}$, the absorption is at least twice smaller that calculated at $\chi=87^{\circ}$. With regard to August 27th, the day to night ratio equal to 2.0 (table III), that is the lower limit indicating a PCA phenomenon (Ranta et al., 1994), suggests a ionospheric absorption essentially due to the solar proton event (started on 24th) rather than the magnetic storm. This could be supported (despite the strong magnetic activity) by the fact that on August 27 th the proton flux remains very high $\left(2.8 \cdot 10^{6}\right.$ counts $\cdot \mathrm{cm}^{-2} \cdot$ day $\left.^{-1} \cdot \mathrm{sr}^{-1}\right)$. April $21 \mathrm{st}$, August 26th and October 1st, for which the day to night ratios are greater than 2.0, confirm the occurrence of PCA phenomena.

Any significant ionospheric absorption decrease from $\chi=87^{\circ}$ to $\chi=102^{\circ}$ can be assessed for the days reported in table II. These days show a day to night ratio smaller than 2.0 that is not typical for a PCA phenomenon as expected (table III). This could suggest that on April 24th and September 25th the ionospheric absorption is more affected by the magnetic storm rather than by the solar protons event. In particular, for September 25th, the proton flux, although occurring by day, remained very small (only $3.4 \cdot 10^{5}$ counts $\cdot \mathrm{cm}^{-2} \cdot$ day $^{-1} \cdot \mathrm{sr}^{-1}$ ) while the magnetic activity was very strong $(\operatorname{ap}(\tau)=94)$. 


\section{Conclusions}

This investigation found that the hourly mean ionospheric absorption calculated at $\chi=96^{\circ}$ is at least two times less than that calculated at $\chi=87^{\circ}$ during a PCA phenomenon. This agrees with what was found by Hargreaves et al. (1993), according to which the electron density is down to half its original value at $\chi=96^{\circ}$.

The hourly mean ionospheric absorption during a PCA phenomenon is always a decreasing function of the solar zenith angle (table I), except for a slight increase observed at $\chi=96^{\circ}$ on August 26th, probably due to the magnetic storm effect that started on that day (fig. 1c). A different behaviour can be observed when the ionospheric absorption is more affected by a magnetic storm rather than by a solar proton event (table II).

Table III shows that when the maximum protons flux occurs by night (21st April, 26th and 27th August) the ionospheric absorption day to night ratios are smaller than that occurring by day (October 1st).

The ionospheric absorption day to night ratio seems to be a suitable index to distinguish the ionospheric absorption due to a solar proton event from that due to a magnetic storm. The cases analysed confirm that a day to night ratio equal to or greater than 2.0 characterizes a PCA phenomenon (Ranta et al., 1984).

An investigation into the absorption peak observed on September 27th (fig. 1c) could be carried out using a different geomagnetic index: as ap $(\tau)$ comes from planetary index $a p$, and concerns above all the $F$ region, the use of a local polar index such as the PC index (Troshichev et al., 1979) could be more suitable to characterize the magnetic storms and hence to better disclose their possible influence on the ionospheric absorption.

\section{Acknowledgements}

The authors would like to thank Dr. G. De Franceschi (INGV-Rome, Italy) for helpful discussions and comments, the Space
Environment Center (NOAA, U.S. Dept. of Commerce, Boulder-CO, U.S.A.) for supplying proton data from GOES satellite, and the Italian National Program of Antarctic Researches (PNRA) for supporting this study.

\section{REFERENCES}

Bremer, J. (1998): Post storm effects in middle and subauroral latitudes, Adv. Space Res., 22,837-840.

Cerrone, M. C. Bianchi, G. De Franceschi and B. ZOLESI (1996): Ionospheric observations at Terra Nova Bay, in Italian Geophysical Observatories in Antarctica, edited by A. MELONI and A. MoRELLI (Istituto Nazionale di Geofisica, Roma), 167-179.

De Franceschi, G., A. De Santis and L. Perrone (1997): Analysis of Riometric data recorded at Terra Nova Bay, Antarctica, in Conference Proceedings of Solar Terrestrial Predictions Workshop, edited by G. Heckman, K. Marubashi, M.A. ShEA, D.F. SMART and R. THOMPSON, 431-434.

De Franceschi, G., T. Gulyaeva, L. Perrone and B. ZOLESI (1999): MAC: an oriented Magnetic Activity Catalogue for ionospheric applications, URSI, International Reference Ionosphere News Letter, 6 (4), 5-6.

HARGREAVES, J.K., A.V. SHIROCHKOV and A.D. FARMER (1993): The polar cap absorption event of 19-21 March 1990: recombination coefficients, the twilight transition and midday recovery, J. Atmos. Terr Phys., 55, 857-862.

Perrone, L. and G. De Franceschi (1999): A correlation study between time-weighted magnetic indices and the high latitude ionosphere, Phys. Chem. Earth (C), 24 (4), 389-392.

Perrone, L., G. De Franceschi and T. Gulyaeva (2001): The time-weighted magnetic indices ap $(\tau)$, $P C(\tau), A E(\tau)$ and their correlation to the southern high latitude ionosphere, Phys. Chem. Earth $(C)$, 26 (5), 331-334.

RANTA, H., A. RANTA and T.J. RosenBERG (1984): The day to night ratio in auroral and subauroral zone riometer measurements during auroral absorption, J. Atmos. Terr. Phys., 46, 395-398.

Troshichev, O.A., N.P. DMitrieva and B.M. KutZnetsov (1979): Polar cap magnetic activity as a signature of substorm development, Planet. Space Sci., 27, 217-221.

WAGNER, C.U., H. RANTA and A. RANTA (1982): Nighttime ionospheric absorption during and after magnetospheric storms from auroral $(L=6.0)$ to medium $(L=2.5)$ latitudes, J. Atmos. Terr. Phys, 9 , 747-757.

WrenN, G.L. (1987): Time-weighted accumulations ap $(\tau)$ and $k p(\tau)$, J. Geophys. Res., 92, 1763-1770.

WU, J. and P.J. WILKINSON (1995): Time-weighted indices as predictors of ionospheric behaviour, $J$. Atmos. Terr. Phys., 57, 1763-1770. 